\title{
Waiting for chikungunya fever in Argentina: spatio-temporal risk maps
}

\author{
Aníbal E Carbajo ${ }^{1,2}{ }^{+}$, Darío Vezzani ${ }^{2,3}$ \\ Ecología de Enfermedades Transmitidas por Vectores, Instituto de Investigación e Ingeniería Ambiental, Universidad Nacional de General \\ San Martín, Buenos Aires, Argentina ${ }^{2}$ Consejo Nacional de Investigaciones Científicas y Técnicas, Buenos Aires, Argentina \\ ${ }^{3}$ Ecología de Reservorios y Vectores de Parásitos, Instituto de Ecología, Genética y Evolución, Universidad de Buenos Aires, Buenos Aires, Argentina
}

Chikungunya virus (CHIKV) transmission has been detected in America in 2013 and recently reached south up to Bolivia, Brazil and Paraguay, bordering countries of Argentina. The presence of the mosquito Aedes aegypti in half of the country together with the regional context drove us to make a rapid assessment of transmission risk. Temperature thresholds for vector breeding and for virus transmission, together with adult activity from the literature, were mapped on a monthly basis to estimate risk. Transmission of chikungunya by Ae. aegypti in the world was seen at monthly mean temperatures from $21-34^{\circ} \mathrm{C}$, with the majority occurring between $26-28^{\circ} \mathrm{C}$. In Argentina temperatures above $21^{\circ} \mathrm{C}$ are observed since September in the northeast, expanding south until January and retreating back to the northeast in April. The maximum area under risk encompasses more than half the country and around 32 million inhabitants. Vector adult activity was registered where monthly means temperatures exceeded $13^{\circ} \mathrm{C}$, in the northeast all over the year and in the northern half from September-May. The models herein proposed show that conditions for transmission are already present. Considering the regional context and the historic inability to control dengue in the region, chikungunya fever illness seems unavoidable.

Key words: Aedes aegypti - vector-borne diseases - alphavirus - South America

Chikungunya fever is a mosquito-borne disease caused by an alphavirus of the family Togaviridae. It is transmitted by the mosquitoes Aedes aegypti and Aedes albopictus, globally known as dengue vectors. Chikungunya virus (CHIKV) was first isolated in Tanzania in 1952, followed by its spread in India and Southeast Asia (Weaver 2014). The disease is currently endemic in parts of Africa, Southeast Asia and on the Indian subcontinent. The first epidemics in Europe occurred in 2007 in northern Italy and in 2010 in southeastern France (ECDC 2014).

In the Americas no transmission of CHIKV has been detected until the recent outbreak started on the island of Saint Martin, in October 2013, and expanded through the Caribbean during the first half of 2014 (ECDC 2014, Weaver 2014). From that onward, the southern countries of the region passed quickly from detecting some imported cases to meet the first autochthonous patients. To March 2015, Bolivia (74 cases), Brazil (149), Colombia (1,317), Ecuador (213), Paraguay (130) and Venezuela $(2,303)$ confirmed local transmission (PAHO 2015). As a consequence, the prospects for controlling CHIKV circulation in Latin America are not good (Weaver 2014) and a high risk of its establishment and spread throughout the tropical, subtropical and even temperate regions of the continent is more real than ever (Vega-Rúa et al. 2014).

doi: 10.1590/0074-02760150005

+Corresponding author: acarbajo@unsam.edu.ar

Received 8 January 2015

Accepted 20 March 2015
Among the three CHIKV genotypes known, the one involved in the American outbreak belongs to the Asian genotype, which could be transmitted by both Ae. aegypti and Ae. albopictus strains from American countries (Vega-Rúa et al. 2014). In Argentina, where more than 50 chikungunya fever imported cases were already reported (PAHO 2015), Ae. albopictus is restricted to the northeastern province of Misiones (Vezzani \& Carbajo 2008) whereas Ae aegypti is present from the northern border to the Patagonian city of Neuquén ( $38^{\circ} 57^{\prime} \mathrm{S}$ $68^{\circ} 03^{\prime} \mathrm{W}$ ) (Grech et al. 2012). However, vector abundances are markedly seasonal through the country, with absence of adult mosquito populations during the winter (Vezzani \& Carbajo 2008). The aim of this paper is to perform a rapid assessment of the current situation and risk of CHIKV transmission in Argentina considering both the seasonal and the spatial scales.

Argentina extends from latitudes $22-55^{\circ}-\mathrm{S}$, presenting subtropical and temperate regions. It has a population of 40 million inhabitants, located mainly in urban environments (91\%). The risk of CHIKV transmission was estimated for the whole country combining conditions for the vector and for the virus. Immunity herd was considered null as there is no record of transmission in the country. Virus income was not studied due to lack of information. A set of 12 monthly risk maps was calculated based on monthly mean temperatures at 2.5 arc-seconds pixel size (worldclim.org) (Hijmans et al. 2005) encompassing the whole country. Each map included different isotherms showing the key temperatures for CHIKV transmission and for vector development. The key temperatures for CHIKV transmission were based on the monthly mean temperatures at which chikungunya fever cases occurred globally. The literature was searched for data on cases for which the location, months of occurrence and potential vector could be identified (Lam et al. 2001, AbuBakar 


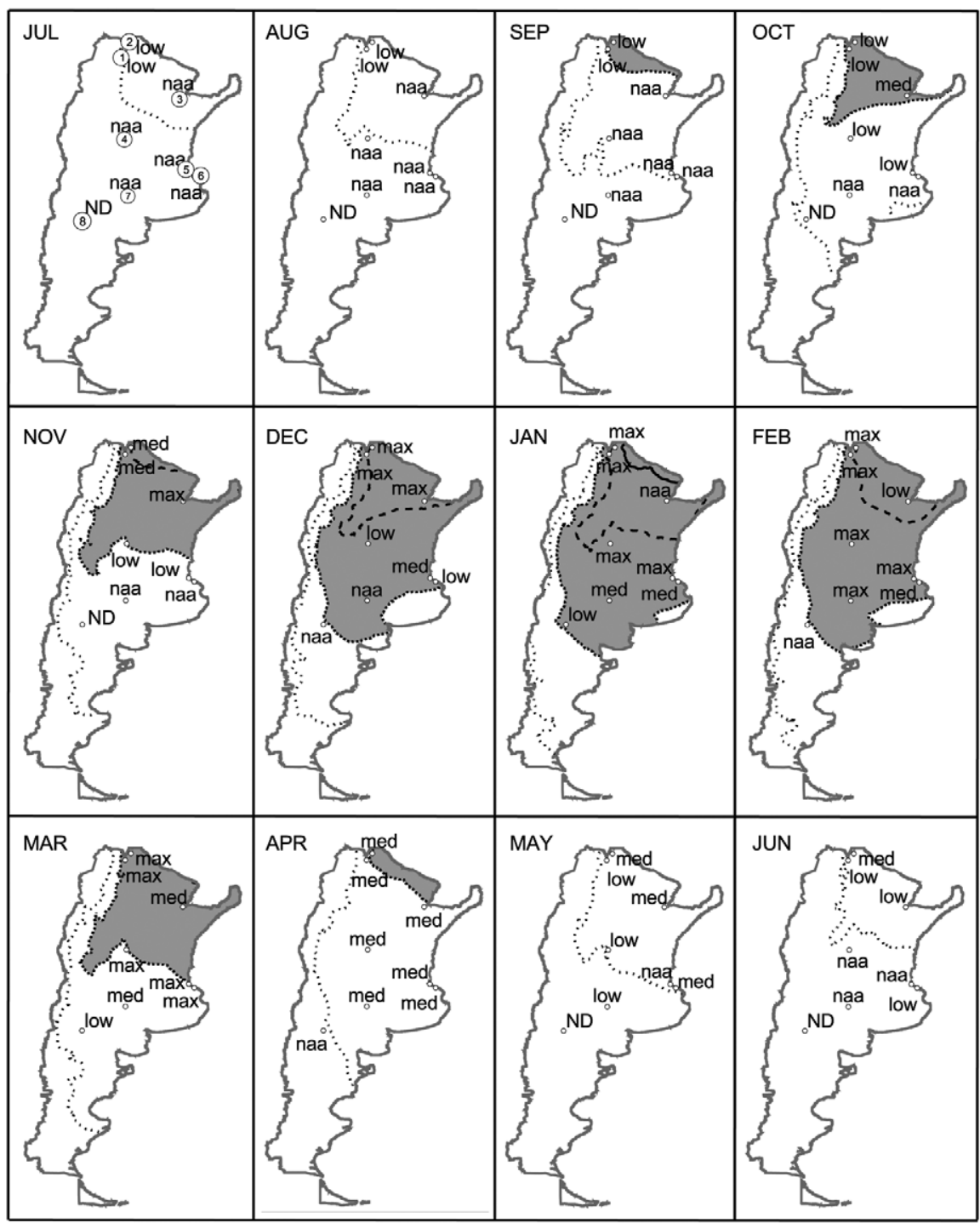

\begin{tabular}{|c|}
\hline CHIKV potential risk \\
Isotherm ${ }^{\circ} \mathrm{C}$ \\
13 \\
21 \\
26 \\
28
\end{tabular}

Monthly risk maps of chikungunya virus (CHIKV) for Argentina based on isotherms of monthly mean temperatures. Lower limit for Aedes aegypti development $\left(13^{\circ} \mathrm{C}\right)$, lower transmission threshold for $\mathrm{CHIKV}\left(21^{\circ} \mathrm{C}\right)$ (grey) and most frequent transmission temperatures $\left(26-28^{\circ} \mathrm{C}\right)$. Adult activity per location, relative to highest month [in descending order maximum (max), medium (med) and low]. Locations included in the study shown in the July map (1: Oran; 2: Tartagal; 3: Resistencia; 4: Córdoba; 5: Buenos Aires; 6: La Plata; 7: Santa Rosa; 8: Neuquén). naa: no adult activity; ND: not detected.

et al. 2007, Her et al. 2009, Tilston et al. 2009, DupontRouzeyrol et al. 2012, Weaver 2014). Only data corresponding to the main potential vector in Argentina $A e$. aegypti was considered, given that Ae. albopictus is restricted to a small area in the northeast of the country. Nine locations from Asia, one from Africa and one from Oceania were obtained, accounting for 45 month-location with transmission. The mean monthly temperature of each month-location was obtained from the web (weatherbase. com/). The most frequent and the lowest temperature of cases occurrence were used as threshold isotherms and mapped in the local risk maps. Key temperatures for the vector development were based on the thermal development threshold (TDT) according to laboratory studies in central Argentina (Domínguez et al. 2000). These authors studied the development rate according to temperature and concluded by extrapolation that $13^{\circ} \mathrm{C}$ might render a null rate. Therefore, maps included $13^{\circ} \mathrm{C}$ isotherm to have 


\section{TABLE}

Frequency of mean monthly temperatures at which chikungunya fever cases occurred worldwide in locations with Aedes aegypti as potential vector

\begin{tabular}{lc}
\hline $\begin{array}{l}\text { Temperature } \\
\left({ }^{\circ} \mathrm{C}\right)\end{array}$ & $\begin{array}{c}\text { Month with cases } \\
\text { (n) }\end{array}$ \\
\hline $21-22$ & 2 \\
$23-25$ & 9 \\
$26-28$ & 20 \\
$29-31$ & 9 \\
$32-33$ & 5
\end{tabular}

data includes successive months for some locations where cases persisted more than a month.

an insight on habitat suitability for the vector. Finally, to supplement the theoretical maps with field data from Argentina, the literature about Ae. aegypti seasonal abundance was revised. The characterisation of this seasonal abundance was based on different measures of adult activity detected by ovitraps: proportion of positive ovitraps per time period [Buenos Aires (Vezzani et al. 2004)], number of eggs per period [Córdoba (Domínguez et al. 2000), Tartagal (Micieli \& Campos 2003), Resistencia (Stein et al. 2005), La Plata (Micieli et al. 2006), Orán (Estallo et al. 2011), Santa Rosa (Breser et al. 2013)], and mosquito detection/non detection per period [Neuquén (Grech et al. 2012)]. One index was chosen from each locality when more than one was available. All the information was unified on a monthly base. For each locality, every month was classified relatively to the highest activity month in four categories: maximum, medium (lower than $60 \%$ of maximum activity), low (lower than $10 \%$ of maximum activity or detection without activity estimate) and no detection. The information was superimposed on the risk maps previously described.

Transmission of CHIKV by Ae. aegypti in the world was observed from $21-34^{\circ} \mathrm{C}$ (Table). The most frequent temperature with transmission was the interval $26-28^{\circ} \mathrm{C}$, accounting for the $44 \%$ of all observed month-locations. In Argentina, the $21^{\circ} \mathrm{C}$ isotherm encompasses the northeast from September-April (Figure). It expands south in the subsequent months reaching its maximum span during January and retreats back to the northeast by April. The maximum area includes more than half the country and around $32,000,000$ inhabitants ( $79 \%$ of Argentinean population). The $26^{\circ} \mathrm{C}$ isotherms covers the northeast since November, then extends south up to central Argentina in January presenting its maximum area and retracts back to the northeast in February. Mean temperatures above $28^{\circ} \mathrm{C}$ are only present in a thin fringe to the very northeast during January.

Regarding mosquito seasonal abundance, all areas below $13^{\circ} \mathrm{C}$ showed no adult mosquito activity, except for Santa Rosa in May and La Plata in June that showed low abundance (Figure). The correlation between abundance classes and temperature intervals was 0.59 (Spearman method, $\mathrm{z}$ $=5.48, \mathrm{p}<0.0001)$. Looking at the $13^{\circ} \mathrm{C}$ isotherm as TDT for the vector, the northeast presents suitable conditions all over the year. The northern half of the country, excluding western highland fringes, has favourable conditions from September until May, whereas south of Neuquén the theoretical suitable period is restricted to November-March.

According to our appraisal, monthly mean temperatures above $21^{\circ} \mathrm{C}$ together with medium or maximum adult activity could be considered the risk threshold. There are areas in the northeast of the country with adequate temperatures for transmission and with medium vector abundances as soon as October. In the most densely populated area, Buenos Aires, the risk begins in December and is sustained until March, when the vector abundance is med-max. In the southern limit of the vector distribution in the continent, close to Santa Rosa and Neuquén, CHIKV transmission could be potentially restricted also to January-February, although the mosquito adult activity known for this region is really low (Grech et al. 2012, Breser et al. 2013). Overall seasonal maximum risk of transmission seems to be limited by virus development more than mosquito abundance.

The models herein proposed show that conditions for transmission are already present. In brief, considering the regional context and the historic inability to control dengue in Argentina, chikungunya fever illness seems unavoidable in the country. As Weaver (2014) remarked in a general way for Latin America, if transmission cannot be controlled quickly, CHIKV will spread throughout the territory.

\section{REFERENCES}

AbuBakar S, Sam I-C, Wong P-F, MatRahim N, Hooi P-S, Roslan N 2007. Reemergence of endemic chikungunya, Malaysia. Emerg Infect Dis 13: 147-149.

Breser VJ, Diez F, Rossi GC, Micieli MV 2013. Determinación del período estacional de oviposición de Aedes aegypti (Diptera: $\mathrm{Cu}-$ licidae) en la ciudad de Santa Rosa, La Pampa, Argentina. Rev Soc Entomol Argent 72: 111-114.

Domínguez C, Ludueña-Almeida FF, Almirón WR 2000. Dinámica poblacional de Aedes aegypti (Diptera: Culicidae) en Córdoba capital. Rev Soc Entomol Argent 59: 41-50.

Dupont-Rouzeyrol M, Caro V, Guillaumot L, Vazeille M, D’Ortenzio E, Thiberge JM, Baroux N, Gourinat AC, Grandadam M, Failloux AB 2012. Chikungunya virus and the mosquito vector Aedes aegypti in New Caledonia (south Pacific Region). Vector Borne Zoonotic Dis 12: 1036-1041.

ECDC - European Centre for Disease Prevention and Control 2014. Chikungunya outbreak in Caribbean region, 25 June 2014, ECDC, Stockholm. Available from: ecdc.europa.eu/en/publications/Publications/chikungunya-caribbean-june-2014-risk-assessment.pdf.

Estallo EL, Ludueña-Almeida F, Scavuzzo CM, Zaidenberg M, Introini MV, Almirón WR 2011. Daily oviposition activity of Aedes aegypti in Orán, Argentina. Rev Saude Publica 45: 977-980.

Grech M, Visintin A, Laurito M, Estallo E, Lorenzo P, Roccia I, Korin M, Goya F, Ludueña-Almeida F, Almirón W 2012. New records of mosquito species (Diptera: Culicidae) from Neuquén and La Rioja provinces, Argentina. Rev Saude Publica 46: 387-389.

Her Z, Kam YW, Lin RTP, Ng LFP 2009. Chikungunya: a bending reality. Microbes Infect 11: 1165-1176.

Hijmans RJ, Cameron SE, Parra JL, Jones PG, Jarvis A 2005. Very high resolution interpolated climate surfaces for global land areas. Int J Climatol 25: 1965-1978. 
Lam SK, Chua KB, Hooi PS, Rahimah MA, Kumari S, Tharmaratnam M, Chuah SK, Smith DW, Sampson IA 2001. Chikungunya infection - an emerging disease in Malaysia. Southeast Asian $J$ Trop Med Public Health 32: 447-451.

Micieli MV, Campos RE 2003. Oviposition activity and seasonal pattern of a population of Aedes (Stegomyia) aegypti (L.) (Diptera: Culicidae) in subtropical Argentina. Mem Inst Oswaldo Cruz 98: 659-663.

Micieli MV, García JJ, Achinelly MF, Martí GA 2006. Dinámica poblacional de los estadios inmaduros del vector del dengue Aedes aegypti (Diptera: Culicidae): un estudio longitudinal (19962000). Rev Biol Trop 54: 979-983.

PAHO - Pan American Health Organization 2015. Number of reported cases of Chikungunya fever in the Americas by country or territory. Available from: paho.org.

Stein M, Oria GI, Almirón WR, Willener JA 2005. Seasonal fluctuation of Aedes aegypti in Chaco province, Argentina. Rev Saude Publica 39: 559-564.
Tilston N, Skelly C, Weinstein P 2009. Pan-European chikungunya surveillance: designing risk stratified surveillance zones. Int $J$ Health Geogr 8: 61.

Vega-Rúa A, Zouache K, Girod R, Failloux AB, Lourenço-de-Oliveira R 2014. High level of vector competence of Aedes aegypti and Aedes albopictus from ten American countries as a crucial factor in the spread of Chikungunya virus. J Virol 88: 6294-6306.

Vezzani D, Carbajo AE 2008. Aedes aegypti, Aedes albopictus and dengue in Argentina: current knowledge and future directions. Mem Inst Oswaldo Cruz 103: 66-74.

Vezzani D, Velázquez SM, Schweigmann N 2004. Seasonal pattern of abundance of Aedes aegypti (Diptera: Culicidae) in Buenos Aires city, Argentina. Mem Inst Oswaldo Cruz 99: 351-356.

Weaver SC 2014. Arrival of chikungunya virus in the New World: prospects for spread and impact on public health. PLoS Negl Trop Dis 8: e2921. 